Note: This is a copy of an article published in the Journal of Complementary and Alternative Medicine () 2011 [copyright Mary Ann Liebert, Inc.]; the Journal of Complementary and Alternative Medicine is available online at: http://online.liebertpub.com.

Full citation: Bishop FL, Massey Y, Yardley L, Lewith GT. (2011). How Patients Choose Acupuncturists: A Mixed Methods Project. Journal of Complementary and Alternative Medicine, 17(1), 19-25. 


\section{How Patients Choose Acupuncturists: A Mixed-Methods Project}

Felicity L. Bishop, PhD, ${ }^{1}$ Yolanda Massey, BSc, ${ }^{2}$ Lucy Yardley, $\mathrm{PhD},{ }^{3}$ and George T. Lewith, MA, DM, FRCP, MRCGP ${ }^{4}$

${ }^{1}$ University of Southampton School of Medicine, Southampton, UK.

${ }^{2}$ University of Bristol, Bristol, UK.

${ }^{3}$ University of Southampton School of Psychology, Southampton, UK.

${ }^{4}$ Aldemoore Health Center, Southampton, UK.

Address correspondence to:

Felicity L. Bishop, PhD

Complementary Medicine Research Unit

Department of Primary Medical Care

School of Medicine

University of Southampton

Aldermoor Health Centre

Aldermoor Close

Southampton SO16 5ST

United Kingdom

E-mail: F.L.Bishop@southampton.ac.uk

\section{Acknowledgments}

The authors would like to thank everyone who took part in these studies and all who facilitated the recruitment process. Dr. Bishop is funded by a Career Development Fellowship from the arthritis research campaign (grant number 18099). Ms. Massey and the costs of this study were funded by the Southampton Complementary Medicine Research Trust. Professor Lewith's post is funded by a grant from the Rufford Maurice Laing Foundation.

\section{Disclosure Statement}

No competing financial interests exist. 


\begin{abstract}
Objectives: Patients can have difficulties choosing acupuncturists in the United Kingdom because acupuncturists are not all subject to statutory regulation. Research has identified factors that influence patients' choice of general practitioner. However, how patients choose acupuncturists has not been studied. The aim was to investigate how patients choose acupuncturists and to identify which factors might influence this choice.
\end{abstract}

Design: A mixed-methods design used an exploratory qualitative study followed by a quantitative study. The qualitative study explored patients' experiences of acupuncture. The quantitative vignette study investigated the impact of patient gender and practitioner factors (gender, training location, and qualifications) on choice of acupuncturist.

Methods: In the qualitative study, 35 acupuncture patients (recruited through maximum variation sampling from seven clinics and the community) participated in semistructured interviews about their acupuncture experiences. In the quantitative study, 73 participants imagined wanting to consult an acupuncturist for back pain. They rated 8 fictional acupuncturists; ratings were analyzed using analysis of covariance.

Results: Patients wanted qualified, personable acupuncturists and valued recommendations from trusted others. Without such recommendations, potential patients preferred female acupuncturists $(\mathrm{F}(1,69)=4.504, \mathrm{p}<0.05)$ and those with medical qualifications $(\mathrm{F}(1,69)=44.832, \mathrm{p}<0.01)$.

Conclusions: The decision to consult a particular acupuncturist is not straightforward. Acupuncturists' trustworthiness and technical competence are important to (potential) patients; practitioner gender also influenced preferences. Patients need to be informed about proposals concerning statutory regulation in CAM and its implications; conventional practitioners might be able to better support their patients wanting to consult acupuncturists. 


\section{Introduction}

The relationship between patient and health care professional (HCP) has well-documented effects on communication and outcomes including patient satisfaction, adherence, and health, within both conventional and complementary health care.[1-5] In the private sector, patients traditionally have the opportunity to choose an HCP, and with the "patient choice" agenda, patients in the public sector are encouraged to do likewise. This can be empowering, but the consumerism associated with patient choice can also be problematic.[6] How patients choose HCPs to consult is thus an important and timely topic.

Much of the existing literature on patient choice of HCP focuses on general practitioners (GP) or obstetricians/gynecologists. Gender has been emphasized and same-sex preferences have been documented, $[7,8]$ which probably depend on the nature of the health problem: They are more commonly expressed in the context of physically and/or psychologically intimate problems than general health problems.[8-10] US data suggest increased gender concordance within primary care from 1995 to 2000,[11] but same-sex preferences are not universal and a minority of women prefer a male HCP in recent obstetrician-gynecologist studies.[12-14] Other demographic characteristics such as ethnicity and age[15-19] may also be important, but questions remain, for example, concerning the relationship between ethnic concordance and outcomes.[20] Patients also consider technical competence and communication style (when relevant indicators are available) $[14,21,22]$ and may value such information above demographic concordance.[23-26] Policy implications have emerged from this literature, such as the need for more female HCPs, but possible explanations of patient preferences have received less attention (although there are exceptions $[8,19]$ ). Anticipated embarrassment might motivate same-sex preferences for intimate problems [27] and/or patients may invoke stereotypical views of the likely skills or communication styles of HCPs.[28] Studies using qualitative methods have shown that preferences for gender and ethnicity-concordant HCPs may stem from beliefs that such HCPs will be more empathic and better able to understand patients' experiences.[14,29]

Complementary and alternative medicine (CAM), specifically acupuncture, presents an additional context for examining patient choice. Patients typically self-refer to CAM, choosing a practitioner from the many available ( $>10,000$ UK-registered acupuncturists provided over 3 million treatments in 1998[30]). Statutory regulation of CAM practitioners is being introduced gradually in the UK, and currently acupuncturists are not subject to statutory regulation (but they do have voluntary regulation, and practitioners such as physiotherapists and GPs who use acupuncture within their practice are regulated). This might be problematic for patients: If anyone can call themselves an acupuncturist, then patients might feel at risk of bodily or financial harm as potential consequences of consulting unqualified practitioners. We know that patients value the empathetic relationships experienced with 
CAM practitioners, [31-35] and patients' perceptions of their CAM practitioner may affect clinical outcome,[36,37] but how patients choose individual CAM practitioners to consult has not been well studied.

We conducted a mixed-methods study to investigate patients' choice of CAM practitioners, focusing on acupuncture. A pragmatic philosophy underpinned our use of mixed methods,[38] and we used a sequential exploratory design.[39] Because little is known about this topic, we began with a qualitative study to explore patients' experiences and used these findings to inform a quantitative study of factors that influence choice of acupuncturist. Ethics approval for both studies was granted by the host institution.

\section{Study 1: Qualitative Study}

$\underline{\text { Aim }}$

The aim was to explore patients' experiences of choosing an acupuncturist.

\section{Materials and methods}

Design, materials, and procedure. The data for this study come from a broader qualitative study using semistructured interviews to explore psychosocial aspects of patients' experiences of acupuncture. The topic guide drew on our previous qualitative work on patients' experiences of CAM. [40] An initial "grand tour" question ("Please tell me all about your experience of acupuncture") was followed up with general probing ("Please tell me more about that') and specific probes if necessary (e.g., "What was the practitioner like?'). Interviews with the first few participants highlighted the importance (for patients) of finding a practitioner, so this was probed more deeply in interviews with subsequent participants. Interviews lasted 24 minutes to 2 hours (median 53 minutes), were audiotaped, transcribed verbatim, and anonymized.

Participants. Six (6) men and 29 women participated (median age $=53$ years). Through maximum variation sampling, 26 participants were recruited from seven clinics (Box 1). Nine (9) participants were recruited through the local community and snowball sampling, in a deliberate attempt to identify people who had 'disappointing, unsuccessful, or negative experiences of acupuncture.' Recruitment stopped on reaching saturation (i.e., no new experiences of finding acupuncturists emerged, main themes were well described).

Analytic methods. All talk about finding an acupuncturist was collated and subject to a thematic analysis.[41,42] After familiarization with the material, low-level, inductive codes were assigned to each meaning unit. Progressively more abstract categories were then developed based on similarities 
and differences between meaning units, until three themes were identified that explained the bulk of the data. FB led the analysis, discussing emerging interpretations with GL. The themes are described below with illustrative verbatim quotes chosen for typicality and clarity.

\section{Findings}

The importance of the decision. Choosing an acupuncturist was not always straightforward, and was described as an important and sometimes challenging process. Annie explained: "You have to be very careful who you go to." The importance of the decision appears to stem in part from the possible risks associated with it: "Where do you go to find out where you should go? Ah, yeah, you go on the web and, you know, you look them all up and you find ones in your area and you look at their qualifications and all this sort of thing. And it's exactly the same with people who do sports massages and everything else. You don't know whether you're safe in their hands.' ( Jennifer). The sense of risk in Jennifer's talk is a reminder that many participants were patients who were seeking (a physically invasive) treatment for an ailment and were thus in a potentially vulnerable position in relation to their practitioner. Ella described how this manifested itself: "To be honest, I think I probably did lie on that table the first day and think oh, I hope she's passed all her exams."'

Relevant characteristics of acupuncturists. Participants talked about two main aspects of an acupuncturist's characteristics: technical competence and personal attributes. A concern that one's chosen acupuncturist would be competent was indicated by talk about qualifications, training, and style of practice, but participants expressed different preferences regarding these issues (Box 2).

Suitable qualifications were necessary but not always sufficient to engender confidence in a potential acupuncturist: “They've all got the qualifications, but like the medics it still doesn't make them a good doctor. And you know if you go to a multi-doctor practice that you'll always say, oh there's no way even if I'm dying I'm going to see him.' ( Jennifer). Concerns about the personal attributes of a potential acupuncturist were expressed in terms of whether a patient thought they would be able to get on with or communicate well with their chosen acupuncturist (Box 3). Gender was a particular concern for some participants; Nelly took her husband to her first two consultations because she was " going to a strange man and thinking I might have to strip off."

How participants found acupuncturists. Participants reported using different means to identify acupuncturists who might be both competent and personable. Social contacts were highly valued, and direct personal recommendations allayed some concerns and were obtained from friends, family members, or colleagues who had consulted a specific acupuncturist: "It's nice to know other people have tried and tested a person. You feel a little more confident about it then, especially if it's a new 
treatment that you've never had before." (Belinda). Without direct recommendations, indirect recommendations were taken from, for example, a friend of a friend. Socially derived confidence in an acupuncturist was also gained through having confidence in the acupuncturist's clinic; for example, Betty ' 'trusted her [the clinic owner] sufficiently to know that she wouldn't have anybody on the premises that was not properly qualified."

Some participants had no social contacts to help them. They searched the limited information in general advertising directories or listings of acupuncturists such as that provided by the British Acupuncture Council. These participants seemed to focus on practical issues such as location: "I went onto the net and the British Acupuncture Society or whatever it was, and I just chose somebody really, looking at the different profiles, but somebody who was near to me'" (Kelly). Some sought phone or e-mail contact with a potential acupuncturist before committing to a consultation: "I e-mailed to ask her if she thought she could help with flying phobia.' (Timothy).

The exception? A few participants did not go through the process of finding an acupuncturist and did not assume the responsibility of identifying and choosing their acupuncturist. These participants were already seeing an HCP who either offered acupuncture themselves or referred on to an acupuncturist. However, these participants still appeared to orient to the issues of competence and personal attributes: "So I was having physiotherapy and she fancies herself as a bit of an acupuncturist and has had training and said, 'Oh, how about trying acupuncture?' So that was why I agreed to try acupuncture. [...] So the fact that I knew her and I'd been going there for 3 months I think gave me a bit of reassurance." (Shelly).

\section{Study 2: Quantitative Study}

\section{$\underline{\text { Aim }}$}

The aim was to test how patients' choice of acupuncturist is influenced by those practitioner characteristics mentioned in the qualitative study that might reasonably be present in advertising directories (gender, training location, qualifications). Patient gender was also investigated, and a gender concordance effect was hypothesized based on the existing literature[8,9] and our qualitative finding that acupuncture is seen as an intrusive intervention (with associated vulnerability).

\section{Materials and methods}

Design. Our mixed $2 \times 2 \times 2 \times 2$ factorial design had three within-subjects factors (practitioner gender; practitioner training location: China/UK; practitioner qualifications: medical/nonmedical) and one between-subjects factor (participant gender). The dependent variable was likelihood of consulting the acupuncturist. This design was adapted from studies of patient preference for other HCPs.[19] 
Participants. A convenience sample of volunteers was recruited from the local community (staff and students at the host institution, and members of a local church), who were informed about the study by e-mail, posters, and word of mouth. The questionnaire was given to volunteers in person or via mail, who then completed it in their own time and returned it to the researchers in person or via freepost mail.

Materials. A vignette-based questionnaire was developed, pilot-tested, and refined using cognitive interviews[43] with 10 volunteers. Box 4 shows the final vignette. Three (3) multiple-choice questions assessed comprehension. Descriptions of 8 fictional acupuncturists representing all permutations of the within-subjects factors (e.g., female acupuncturist, trained in the United Kingdom, qualified as a GP) were formatted to look like an advertisement (enhancing ecological validity). Participants rated each acupuncturist according to how likely they would be to make an appointment with them (10point numerical Likert scale; 10 indicates certainly would consult).

Statistical methods. Using SPSS 16, a mixed-design analysis of covariance (ANCOVA) tested the impact of practitioner characteristics and patient gender on likelihood of consulting. Previous experience of acupuncture and back pain were covariates. Two-way interactions were investigated using $t$ tests. Higher-order interactions were not interpreted because of the exploratory nature of the analysis and the lack of any a priori rationale for such complex effects.

$\underline{\text { Results }}$

Participants' characteristics

Seventy-nine (79) participants returned completed questionnaires. Six (6) answered the comprehension questions incorrectly and were excluded, giving a final sample of 73 people (43 women) aged 19-83 years (mean $[\mathrm{M}]=43.9$, standard deviation $[\mathrm{SD}]=9.0$ ). Table 1 shows further characteristics.

\section{Choice of acupuncturist}

Table 2 shows the ANCOVA results. Participants preferred female acupuncturists (female acupuncturists $\mathrm{M}=6.34, \mathrm{SD}=1.85$; male acupuncturists $\mathrm{M}=5.66, \mathrm{SD}=1.98$ ). They preferred acupuncturists with medical qualifications $(\mathrm{M}=7.07, \mathrm{SD}=1.84$; no medical qualifications $\mathrm{M}=4.95$, $\mathrm{SD}=2.14)$. There was no effect of training location or participant gender. Neither previous experience of acupuncture nor back pain had a significant main effect. 
The interaction between practitioner gender and training location was because training location had no impact on ratings of female practitioners (trained in China $\mathrm{M}=6.36, \mathrm{SD}=2.00$; trained in $\mathrm{UK} \mathrm{M}=6.36$, $\mathrm{SD}=1.99 ; \mathrm{t}(72)=0.039$, not significant $[\mathrm{ns}])$, but male practitioners who were trained in China were preferred to those who were trained in the United Kingdom (trained in China $\mathrm{M}=6.21, \mathrm{SD}=2.08$; trained in $\mathrm{UK} \mathrm{M}=5.12, \mathrm{SD}=2.28 ; \mathrm{t}(72)=5.1, \mathrm{p}<0.01)$. There was a significant interaction between practitioner gender and medical qualifications in that there was no effect of gender on ratings of nonmedically qualified acupuncturists (female $\mathrm{M}=5.03, \mathrm{SD}=2.16$; male $\mathrm{M}=4.89, \mathrm{SD}=2.23 ; \mathrm{t}(72)=1.495$, $\mathrm{ns}$ ), but female medical acupuncturists were rated higher than male medical acupuncturists (female $\mathrm{M}=7.68, \mathrm{SD}=1.97$; male $\mathrm{M}=6.45, \mathrm{SD}=1.97 ; \mathrm{t}(72)=7.649, \mathrm{p}<0.01)$. There was a significant interaction between training location and medical qualifications: There was no effect of training location on ratings of non-medically qualified acupuncturists (trained in China $\mathrm{M}=5.01, \mathrm{SD}=2.32$; trained in United Kingdom $\mathrm{M}=4.90, \mathrm{SD}=2.29 ; \mathrm{t}(72)=0.554, \mathrm{~ns})$, but among medically qualified acupuncturists, those who were trained in China were rated higher (trained in China $\mathrm{M}=7.56, \mathrm{SD}=2.06$; trained in United Kingdom $\mathrm{M}=6.58, \mathrm{SD}=2.03 ; \mathrm{t}(72)=4.805, \mathrm{p}<0.01)$.

\section{Discussion}

We believe that this is the first project to focus on patients' choice of CAM practitioners. By using a sequential mixed methods design, we benefited from the strengths of both qualitative and quantitative approaches. In the qualitative study, people using acupuncture for various conditions oriented to the task of choosing an acupuncturist, and some saw it as challenging and somewhat risky. Our analysis suggested that patients were concerned about potential acupuncturists' technical competence and personal attributes, and social contacts and recommendations were important. The quantitative study then tested the effect of specific factors on choice of acupuncturist in a larger sample using a balanced experimental design and controlling for likely confounders. Here, our potential acupuncture patients referred female acupuncturists and those with medical qualifications. The interactions will not be discussed, and should first be replicated.

In the vignette study, we had expected to replicate the literature on choice of HCP for intimate problems and to find a gender-concordance effect.[8,9] Although back pain is not an intimate problem, acupuncture is an invasive treatment involving physical contact between acupuncturist and patient. Furthermore, the qualitative study had suggested that patients are attuned to an element of physical vulnerability that resonates with the idea of anticipated embarrassment when consulting for intimate problems. However, the vignette study found that both female and male participants preferred female acupuncturists. Both findings could be true: The link between vulnerability and gender may be an important minority concern that can be highlighted in small scale qualitative work using maximum variation sampling, but would be obscured by dominant majority views in a larger 
quantitative study. Our potential patients may have differed from our actual patients in not considering that having acupuncture involves a sense of gender-based vulnerability, which may be more prominent when one is actually about to have acupuncture. Perhaps our potential male and female patients preferred female acupuncturists because they drew on social stereotypes of women as more empathic or personable.[14,28,29]

Medical qualifications also influenced potential patients' preferences in the vignette study. Our potential patients as a group, like some of our actual patients, probably perceived medical qualifications as indicating technical competence or as constituting a "safety net." This suggests a need to raise awareness about acupuncture qualifications, and the lack of any established correlation between medical training and competence in acupuncture. In the qualitative study, patients reported seeking acupuncturists who were both technically competent and personable. Technical competence was complex, and having medical qualifications, certain training locations, and specific styles of acupuncture were seen as positive and negative by different participants. Acupuncture patients' concern to be able to "get on with" an acupuncturist echoes existing qualitative literature on the importance of therapeutic relationships in CAM.[34,35] When possible, patients preferred to select acupuncturists based on recommendations from their social network, potentially incorporating information about an acupuncturist's competence and personal character. However, these attributes seemed harder to ascertain for those using directories. While directories might provide at least some information about an acupuncturist's qualifications, they are less likely to provide information about personal characteristics. Perhaps potential patients (like those in the vignette study) elaborate their representations of listed acupuncturists by attending to the limited cues available (such as gender) and invoking cultural stereotypes (e.g., of empathic women) and/or similar previous experiences (e.g., of the communication style of female doctors previously consulted). This hypothesis requires formal testing in future experiments.

Our conclusions are limited by methodological weaknesses, primarily the convenience sample in the vignette study (recruited from a local church and the university community). This study should be repeated using a representative sample of either the general population or the somewhat more nebulous population of people considering acupuncture. Practitioner's ethnicity (e.g., Chinese or English) could also be investigated[15-17] and is particularly relevant given the origins of acupuncture. The interpretation of vignette studies could be enhanced by incorporating "think aloud" methods to examine participants' explicit reasoning.

\section{Conclusions}


Choice of acupuncturist occurs in a context of potential risk, and patients might benefit from HCPs' support in making such choices. For example, HCPs might direct patients to reliable information about recognized acupuncture qualifications. Further work is needed with larger, more representative samples of the general population, to clarify which factors impact choice of practitioner in order to inform the development of such support. Our theoretical understanding might also be advanced by directly comparing patients' choice of CAM practitioners with their choice of other, conventional, HCPs. 


\section{References}

1. Bishop FL, Yardley L, Lewith GT. Treatment appraisals and beliefs predict adherence to complementary therapies: A prospective study using a dynamic extended self-regulation model. $\mathrm{Br} \mathrm{J}$ Health Psychol 2008;13:701-718.

2. Di Blasi Z, Harkness E, Ernst E, et al. Influence of context effects on health outcomes: A systematic review. Lancet 2001;357:757-762.

3. Little P, Everitt $\mathrm{H}$, Williamson I, et al. Observational study of effect of patient centredness and positive approach on outcomes of general practice consultations. BMJ 2001;323:908-911.

4. Hall JA, Roter DL. Do patients talk differently to male and female physicians? A meta-analytic review. Patient Educ ouns 2002;48:217-224.

5. Sandhu H, Adams A, Singleton L, et al. The impact of gender dyads on doctor-patient communication: A systematic review. Patient Educ Couns 2009;76:348-355.

6. Lupton D. Consumerism, reflexivity and the medical encounter. Soc Sci Med 1997;45:373-381.

7. Hopkins EJ, Pye AM, Solomon M, Solomon S. A study of patients' choice of doctor in an urban practice. J R Coll Gen Pract 1967;14:282-288.

8. Kerssens JJ, Bensing JM, Andela MG. Patient preference for genders of health professionals. Soc SciMed 1997;44:1531-1540.

9. Nichols S. Women's preferences for sex of doctor: A postal survey. J R Coll Gen Pract 1987;37:540-543.

10. Bensing JM, van den Brink-Muinen A, de Bakker DH. Gender differences in practice style: A Dutch study of general practitioners. Med Care 1993;31:219-229.

11. Fang MC, McCarthy EP, Singer DE. Are patients more likely to see physicians of the same sex? Recent national trends in primary care medicine. Am J Med 2004;117:575-581.

12. Johnson AM, Schnatz PF, Kelsey AM, Channessian CM. Do women prefer care from female or male obstetrician-gynecologists? A study of patient gender preference. J Am Osteopath Assoc 2005;105:369-379.

13. Lund JD, Rohrer JE, Goldfarb S. Patient gender preferences in a large military teaching hospital. Obstet Gynecol 2005;105:747-750.

14. Howell EA, Gardiner B, Concato J. Do women prefer female obstetricians? Obstet Gynecol 2002;99:1031-1035.

15. Tarn DM, Meredith LS, Kagawa-Singer M, et al. Trust in one's physician: The role of ethnic match, autonomy, acculturation, and religiosity among Japanese and Japanese Americans. Ann Fam Med 2005;3:339-347.

16. Ahmad WIU, Kernohan EEM, Baker MR. Patients' choice of general practitioner: Influence of patients' fluency in English and the ethnicity and sex of the doctor. J R Coll Gen Pract 1989;39:153155 . 
17. Ahmad WIU, Kernohan EEM, Baker MR. Patients' choice of general practitioner: Importance of patients' and doctors' sex and ethnicity. Br J Gen Pract 1991;41:330-331.

18. Furnham A, Swami V. Patient preferences for dentists. Psychol Health Med 2009;14:143-149.

19. Furnham A, Petrides KV, Temple J. Patient preferences for medical doctors. Br J Health Psychol 2006;11:439-449.

20. Meghani SH, Brooks JM,Gipson-Jones T, et al. Patient-provider race-concordance: Does it matter in improving minority patients' health outcomes? Ethn Health 2009;14:107-130.

21. Mavis B, Vasilenko P, Schnuth R, et al. Female patients' preferences related to interpersonal communications, clinical competence, and gender when selecting a physician. Acad Med 2005;80:1159-1165.

22. Cheraghi-Sobi S, Hole AR, Mead N, et al. What patients want from primary care consultations: A discrete choice experiment to identify patients' priorities. Ann Fam Med 2008;6:107-115.

23. Newton FJ, Ewing MT, Burney S, Vella-Brodrick D. Medical clinic facilities and doctor characteristics: What older rural men value. Aust J Rural Health 2007;15:41-45.

24. Fung CH, Elliott MN, Hays RD, et al. Patients' preferences for technical versus interpersonal quality when selecting a primary care physician. Health Serv Res 2005;40:957-977.

25. Piper I, Shvarts S, Lurie S. Women's preferences for their gynecologist or obstetrician. Patient Educ Couns 2008;72:109-114.

26. Schnatz PF, Murphy JL, O’Sullivan DM, Sorosky JI. Patient choice: Comparing criteria for selecting an obstetrician-gynecologist based on image, gender, and professional attributes. Am J Obstet Gynecol 2007;197:548e.1-548e.7.

27. Rizk DEE, El-Zubeir MA, Al-Dhaheri AM, et al. Determinants of women's choice of their obstetrician and gynecologist provider in the UAE. Acta Obstet Gynecol Scand 2005;84:48-53.

28. Ahmad F, Gupta H, Rawlins J, Stewart DE. Preferences for gender of family physician among Canadian European descent and South-Asian immigrant women. Fam Pract 2002;19:146-153.

29. Garcia JA, Paterniti DA, Romano PS, Kravitz RL. Patient preferences for physician characteristics in university-based primary care clinics. Ethn Dis 2003;13:259-267.

30. Thomas KJ, Nicholl JP, Coleman P. Use and expenditure on complementary medicine in England: A population based survey. Complement Ther Med 2001;9:2-11.

31. Gould A, MacPherson H. Patient perspectives on outcomes after treatment with acupuncture. J Altern Complement Med 2001;7:261-268.

32. Canales MK, Geller BM. Surviving breast cancer. The role of complementary therapies. Fam Community Health 2003;26: 11-24.

33. Luff D, Thomas KJ. 'Getting somewhere', feeling cared for: Patients' perspectives on complementary therapies in the NHS. Complement Ther Med 2000;8:253-259.

34. Cassidy CM. Chinese medicine users in the United States: Part II. Preferred aspects of care. J Altern Complement Med 1998;4:189-202. 
35. Paterson C, Britten N. Acupuncture as a complex intervention: A holistic model. J Altern Complement Med 2004;10:791-801.

36. Berk SN, Moore ME, Resnick JH. Psychosocial factors as mediators of acupuncture therapy. J Consult Clin Psychol 1977;45:612-619.

37. Price S, Mercer SW, MacPherson H. Practitioner empathy, patient enablement and health outcomes: A prospective study of acupuncture patients. Patient Educ Couns 2006;63:239-245.

38. Yardley L, Bishop FL. Mixing qualitative and quantitative methods: A pragmatic approach. In: Willig C, Stainton Rogers W, eds. The Sage Handbook of Qualitative Research in Psychology. Sage: London, 2008;352-370.

39. Creswell JW, Plano Clark VL. Designing and Conducting Mixed Methods Research. Thousand Oaks, CA: Sage, 2006.

40. Bishop FL, Yardley L, Lewith GT. Treat or treatment: A qualitative study conceptualising patients' use of complementary and alternative medicine (CAM). Am J Public Health 2008;98:17001705.

41. Joffe H, Yardley L. Content and thematic analysis. In: Marks DF, ed. Research Methods for Clinical and Health Psychology. London: Sage, 2004:56-68.

42. Braun V, Clarke V. Using thematic analysis in psychology. Qual Res Psychol 2006;3:77-101.

43. Collins D. Pretesting survey instruments: An overview of cognitive methods. Qual Life Res 2003;12:229-238. 
Box 1. Dimensions Used to Guide Maximum Variation Sampling, and Characteristics Present in Our Final Sample (Study 1)

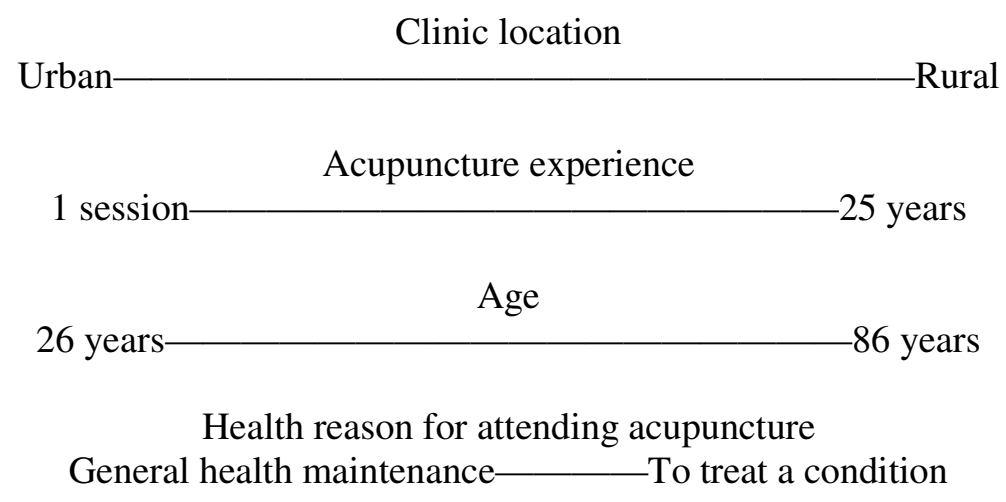

Examples of conditions that acupuncture was used for Hay fever, rheumatoid arthritis, smoking cessation, IBS, headache, back pain, anxiety, fear of flying 
"I think that would be my main concern about considering it here again, is how well somebody's actually been prepared to do it [...]. You probably have to really sort of do some homework about, you know, who's offering it and what their qualifications are. How well qualified they are to do it." (Lisa)

"And I was particularly pleased that [acupuncturist] is dual qualified. As with a number of other alternative treatments, I do like the person to have a strong background in conventional Western medicine in case there's something there that they were to spot which wears the Western hat." (Carl)

“I knew of 2 people and they just go to their doctors who've been on a short course, enough to be able to push a needle into you. But do they know, learn, enough on a short course? I rather compare them with [acupuncturist]who did 7 years'training." (Annie) 
Box 3. Participants Talk About the Personal Attributes of Acupuncturists

"And in truth you have to get on with an acupuncturist, so if I hadn't have liked him I would have gone elsewhere." (Alison)

“'They've got to be somebody who's interesting ideally to talk to as well, because if it comes to an emotional rollercoaster when things go right or things go wrong, then you want somebody who can listen, so you want someone who's a good listener.' (Emily, who was using acupuncture alongside infertility treatment) 
Imagine that you have been suffering back pain recently. Despite several visits to your general practitioner, there seems to be no conventional treatment that works for you. Both your doctor and a good friend recommend trying acupuncture. You decide to have acupuncture. Your doctor recommends a local acupuncture centre. Eight (8) acupuncturists work at the centre. Each acupuncturist is British, and was born and raised in the United Kingdom. They all speak English as their first language. On the following page are the names of all 8 acupuncturists. They are all registered members of the British Acupuncture Council (MBAcC). All practitioner members of the British Acupuncture Council are fully qualified and observe strict Codes of Ethics and Practice. Some are trained in conventional Western medicine as well: They practice as doctors. 
Table 1. Study 2 Participants' Characteristics

\begin{tabular}{|l|l|}
\hline Characteristic & Proportion of Sample (n) \\
\hline Postsecondary education & $89 \%(65)$ \\
\hline Longstanding health condition & $35 \%(26)$ \\
\hline Experience of back pain (ever) & $55 \%(40)$ \\
\hline Experience of back pain (in past 12 months) & $37 \%(27)$ \\
\hline Experience of back pain (current) & $11 \%(8)$ \\
\hline Use of acupuncture (ever) & $18 \%(13)$ \\
\hline Use of any CAM (ever) & $59 \%(43)$ \\
\hline
\end{tabular}

CAM, complementary and alternative medicine. 
Table 2. Mixed-Design Analysis of Covariance Results: Effects of Practitioner and Patient Characteristics on Patient Preferences for Acupuncturists

\begin{tabular}{|c|c|c|}
\hline Source & $\mathrm{F}(1,69)$ & Partial eta-squared \\
\hline Practitioner gender & $4.504 *$ & 0.061 \\
\hline Medical qualifications & $44.832 * *$ & 0.394 \\
\hline Training location & 1.128 & 0.016 \\
\hline Participant gender & 0.181 & 0.003 \\
\hline Ever acupuncture & 0.063 & 0.001 \\
\hline Ever back pain & 1.193 & 0.017 \\
\hline Practitioner gender $\mathrm{x}$ Participant gender & 2.827 & 0.039 \\
\hline Practitioner gender $\mathrm{x}$ Training location & $23.327 * *$ & 0.253 \\
\hline Practitioner gender x Medical qualifications & $17.467 * *$ & 0.202 \\
\hline Practitioner gender x Ever acupuncture & $9.788 * *$ & 0.124 \\
\hline Practitioner gender $\mathrm{x}$ Ever back pain & 1.732 & 0.024 \\
\hline Training location $\mathrm{x}$ Medical qualifications & $11.976 * *$ & 0.148 \\
\hline Training location $\mathrm{x}$ Participant gender & 0.182 & 0.003 \\
\hline Training location $\mathrm{x}$ Ever acupuncture & 1.651 & 0.023 \\
\hline Training location $\mathrm{x}$ Ever back pain & 0.353 & 0.005 \\
\hline Medical qualifications x Participant gender & 0.098 & 0.001 \\
\hline Medical qualifications x Ever acupuncture & 0.018 & 0.000 \\
\hline Medical qualifications $\mathrm{x}$ back pain & 2.081 & 0.029 \\
\hline $\begin{array}{l}\text { Practitioner gender } \mathrm{x} \text { Participant gender } \mathrm{x} \\
\text { Training location }\end{array}$ & 0.141 & 0.002 \\
\hline $\begin{array}{l}\text { Practitioner gender } \mathrm{x} \text { Participant gender } \mathrm{x} \\
\text { qualifications }\end{array}$ & 0.006 & 0.000 \\
\hline $\begin{array}{l}\text { Practitioner gender } \mathrm{x} \text { Training location } \mathrm{x} \\
\text { Medical qualifications }\end{array}$ & $9.735 * *$ & 0.124 \\
\hline $\begin{array}{l}\text { Practitioner gender } \mathrm{x} \text { Training location } \mathrm{x} \\
\text { Ever acupuncture }\end{array}$ & $4.210^{*}$ & 0.058 \\
\hline $\begin{array}{l}\text { Practitioner gender } \mathrm{x} \text { Training location } \mathrm{x} \\
\text { Ever back pain }\end{array}$ & 0.001 & 0.000 \\
\hline $\begin{array}{l}\text { Practitioner gender x Medical qualifications } \\
\text { x Ever acupuncture }\end{array}$ & 1.905 & 0.027 \\
\hline $\begin{array}{l}\text { Practitioner gender x Medical qualifications } \\
\mathrm{x} \text { Ever back pain }\end{array}$ & 0.382 & 0.006 \\
\hline $\begin{array}{l}\text { Training location } \mathrm{x} \text { Medical qualifications } \mathrm{x} \\
\text { Participant gender }\end{array}$ & 0.161 & 0.002 \\
\hline $\begin{array}{l}\text { Training location } \mathrm{x} \text { Medical qualifications } \mathrm{x} \\
\text { Ever acupuncture }\end{array}$ & 0.755 & 0.011 \\
\hline $\begin{array}{l}\text { Training location } \mathrm{x} \text { Medical qualifications } \mathrm{x} \\
\text { Ever back pain }\end{array}$ & 0.048 & 0.001 \\
\hline $\begin{array}{l}\text { Practitioner gender } \mathrm{x} \text { Training location } \mathrm{x} \\
\text { Medical qualifications } \mathrm{x} \text { Participant gender }\end{array}$ & 0.329 & 0.005 \\
\hline $\begin{array}{l}\text { Practitioner gender x Training location } \mathrm{x} \\
\text { Medical qualifications x Ever acupuncture }\end{array}$ & 2.756 & 0.038 \\
\hline $\begin{array}{l}\text { Practitioner gender } \mathrm{x} \text { Training location } \mathrm{x} \\
\text { Medical qualifications } \mathrm{x} \text { Ever back pain }\end{array}$ & 1.498 & 0.021 \\
\hline
\end{tabular}

